\title{
Samtskhe-Javakheti Agriculture Sectors Development and its Ecological Problems
}

\author{
Revaz Tolordava ${ }^{1,}$,, Malkhaz Gvinjilia ${ }^{1}$, Koba Korsantia ${ }^{1}$, Tengiz Gordeziani ${ }^{2}$, Zurab Laoshvili $^{2}$ \\ ${ }^{1}$ Department of Geography, Faculty of Natural Sciences and Healthcare, Sokhumi State University, Tbilisi, Georgia \\ ${ }^{2}$ Department of Geography, Faculty of Exact and Natural Sciences, Tbilisi State University, Tbilisi, Georgia
}

Email address:

rezo_06@mail.ru (R. Tolordava)

\section{To cite this article:}

Revaz Tolordava, Malkhaz Ghvinjilia, Koba Jorsantia, Tengiz Gordezni, Zurab Laoshvili. Samtskhe-Javakheti Agriculture Sectors Development and its Ecological Problems. Earth Sciences. Special Issue: Modern Problems of Geography and Anthropology.

Vol. 4, No. 5-1, 2015, pp. 41-45. doi: 10.11648/j.earth.s.2015040501.18

\begin{abstract}
The paper presents the modern condition analyses and development prospects of the main agriculture sectors of a mountainous region in the southern part of Georgia - Samtskhe-Javakheti. On the basis of literary sources and internet material examination, certain sectors' value in provisioning of republic has been assessed. The importance of agricultural sector vectoring in the side agriculture has been outlined. Results of the research are interpreted in charts and graphic models. Field research process has revealed a growing number of ecological problems related to biological and household waste and also caused by "chemicalization". The research has shown that the issues about protection from soil erosion and the water supply acute in the region. It greatly hinders the development of agriculture and it's a great challenge for the region's population, who are mostly employed in the agricultural sector. During the research, different types of humus and soil nutrient elements supplies, soil structure and physical properties were investigated. Ecological problems solution and agricultural production's sustainable development activation, which will ensure ecological condition improvement in agricultural sectors, healthy products production and that will create a firm foundation for withdrawing the agricultural production import, are considered to be the main challenges of the region.
\end{abstract}

Keywords: Samtskhe-Javakheti, Agriculture, Ecological Problems

\section{Introduction}

Meeting and increasing demand of the mankind for food products determines the steady growth of agricultural production. In addition, in republic with a small landowner and difficult terrain as Georgia is, this can be achieved only by the growth of productivity that acquires regions "sectors" development and modern technologies maintenance.

This, of course, involves the use of chemicals. It is well known fact that agricultural products quality partially depends on the ecological condition of the environment. In addition, in the battle of healthy products provision, the increasing rate of agriculture "chemicalization" is one of the disturbing phenomena[1]. Therefore, it is of the greatest importance to find solutions to environmental problems and to develop scientifically justified fundamentals. So, modern methods introduction for protecting plants from pests and scientific study of environmental protection represents global ecological problem of XXI century [2]. In the world, ongoing global processes are directly related to the scale of agricultural growth, which caused earth's natural resources utilization and environmental pollution's unprecedented growth forcing human look for ways of ecological problems solution.

Research has been based on the various literary sources and field-work.

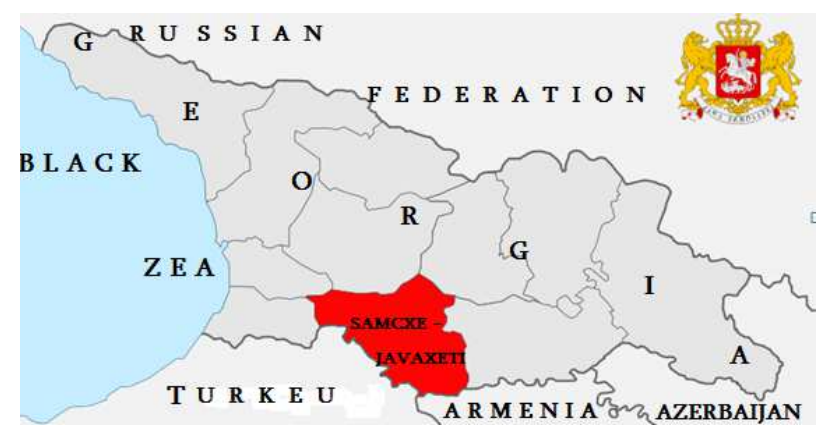

Fig. 1. Location of Samtskhe-Javakheti.

The aim of the research is to study and analyze the main 
ecological problems facing agricultural condition and sector (Fig. 1) of one of the most important agricultural region of Georgia - Samtskhe-Javakhet [3].

\section{Main Results}

The most distinctive agricultural region of Samtskhe-Javakheti republic is the place where agriculture has historically played the greatest role [4]. Against the background of the mountain regions, the side is relatively well provided with natural agricultural resources [5]. Such situation is still preserved. In the land fund, the biggest place (70\%) comes from pastures (Fig. 2).

Since the majority of the population of Georgia settled in the city and in some of its regions a particular sector of industry has been developed, agriculture still remained leading field for Samtskhe-Javakheti [6]. Even more, region "loading" in those terms has been increased, because of the fact that region's agriculture not only supplied city's population with products, but was also providing necessary raw materials for many sectors of industry.

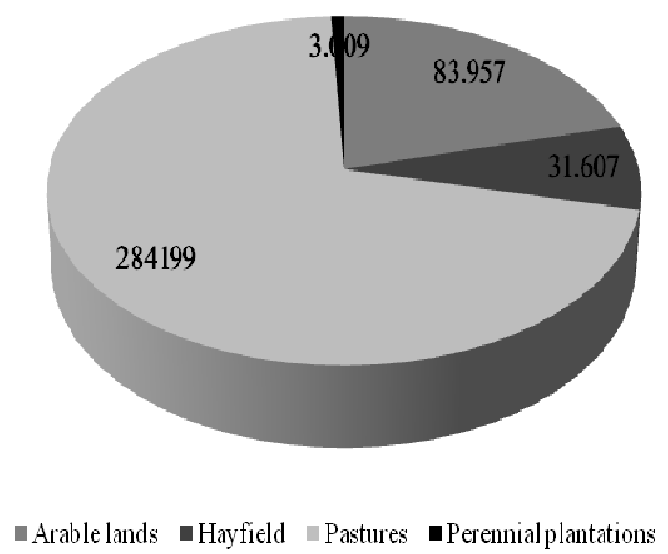

Figure 2. Distribution of Agricultural Lands of Samtskhe-Javakheti.

During Soviet times, the high specialization of agriculture in light of the scarcity of land, had most negative impact on such sectors of agriculture, such as the grain farming and cattle-breeding [7]. This was reflected in Javakheti's agriculture too.

Currently, the share of agriculture in the region is produced in gross domestic product (GDP) (in the region $49 \%$, in the country on an average $9.3 \%$ ) and in the total additional cost (32\%).This rate was approximately $33 \%$ in 2006-2011, and in other sectors of the region and comparing with the rest of regions" index, it was the highest one . In addition, the biggest part of human resources is employed in this sector. In this side, approximately 60,000 households have their own thrift.

Thus, region agriculture is mainly represented by households, where more than $90 \%$ of production is concentrated (with commercial farms). $73 \%$ of them produce agricultural products mainly for their own consumption, while for the rest $27 \%$ agriculture represents the source of income. In addition, nationally, Samtskhe-Javakheti region's agriculture commercialization level is higher than agriculture commercialization indicator .

In recent years, agricultural crops areas have experienced a slight increase, but, in 2009-2012, almost 20\% amid increasing, since 2013 the downward trend has been observed (Fig 3).

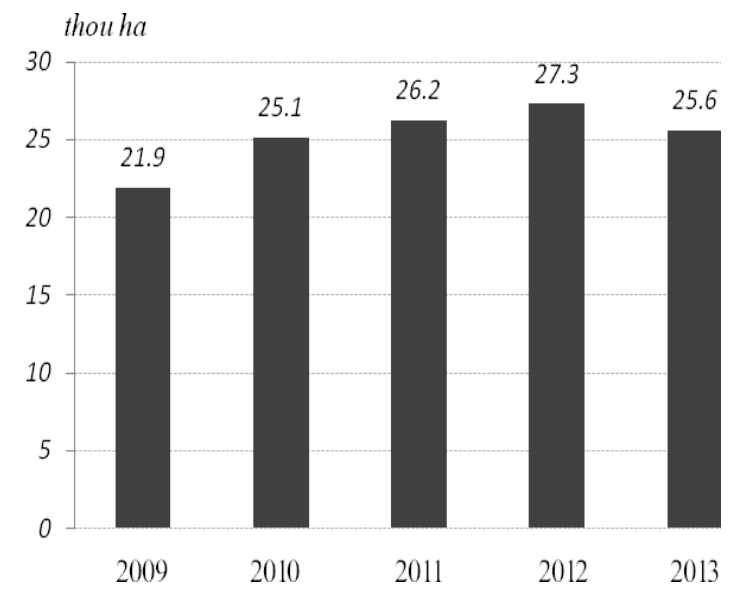

Figure 3. Agricultural crops areas dynamics in Samtskhe-Javakheti.

During 2000-2011 period it was decreasing and according to data of 2013, in Georgia, it was $8 \%$ of total area of annual crops.

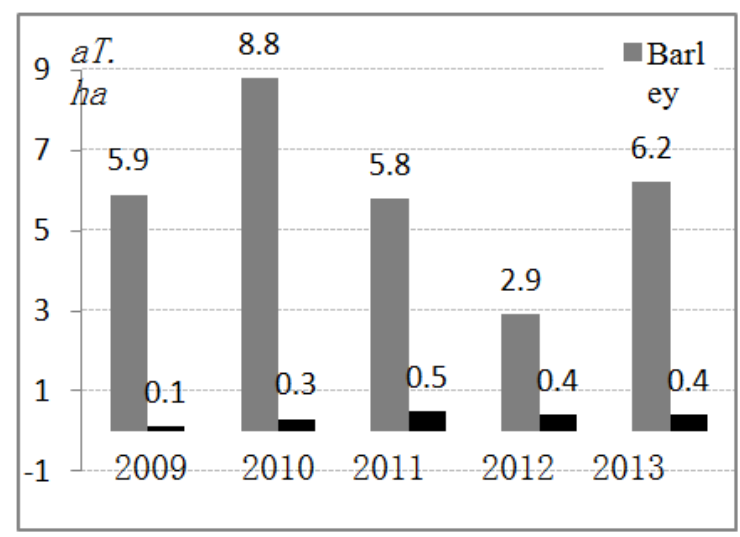

Figure 4. Area of Barley and Beans 2011-2013[2].

Approximately analogical tendency is typical for dynamics of barley crops (Fig. 4). However, in spite of the fact that it is leading In Georgia, as its productivity so its production - by its share is approximately $42 \%$ (area $35 \%$ ), while the average productivity is $18 \%$ higher than Country's average indicator. In 2011-2013 the average productivity of barley was 1.5-2.0 $\mathrm{t} / \mathrm{ha}$, while the average indicator of Georgia did not exceed 1.3-1.9 t/ha. Considering bean crop areas, Samtskhe-Javakheti significantly lags behind other Regions producing this culture (Shida Kartli, Kvemo Kartli, Mtskheta-Mtianeti, Kakheti), in spite of productivity reduction from 2 to $6 \mathrm{t} / \mathrm{ha}$, during these years this culture with the average yield was again the leader.

Despite this fact, crops are very important for republic. In the region area and crop volume connected with it, has often been changed and despite decrease tendency (2011-2012 
years), in 2013 has outrun 2009 year data, though it still lags behind the level of 2010 year (maximum) .

In Samtskhe-Javakheti in descending order is characterized one-year of grasses production that is caused by reduction as of the area so of the productivity. However, this tendency is less typical for perennial herbs production.

Table 1. Area and Productivity of Potato.

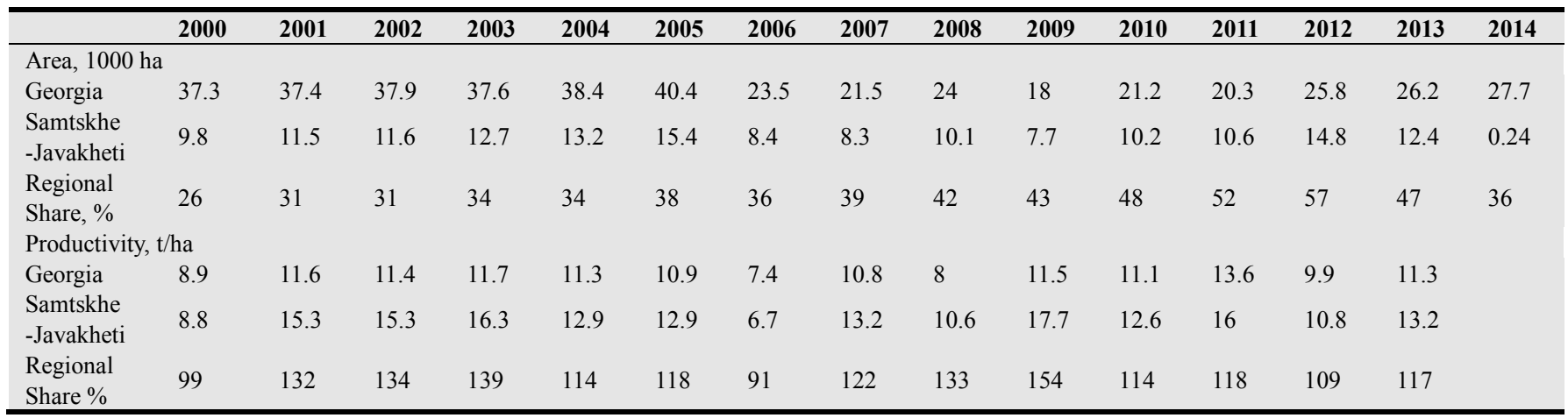

The first place in plant-growing holds potato. In the country, the significant share of its production is in Samtskhe-Javakheti that was achieved by the size of area (in the country $52 \%$ $-2011 ; 47 \%$ - 2013 of taken area by this culture) and significant increasing of region productivity (the averadge yield on average $22 \%$ higher) (Tab. 1 ).

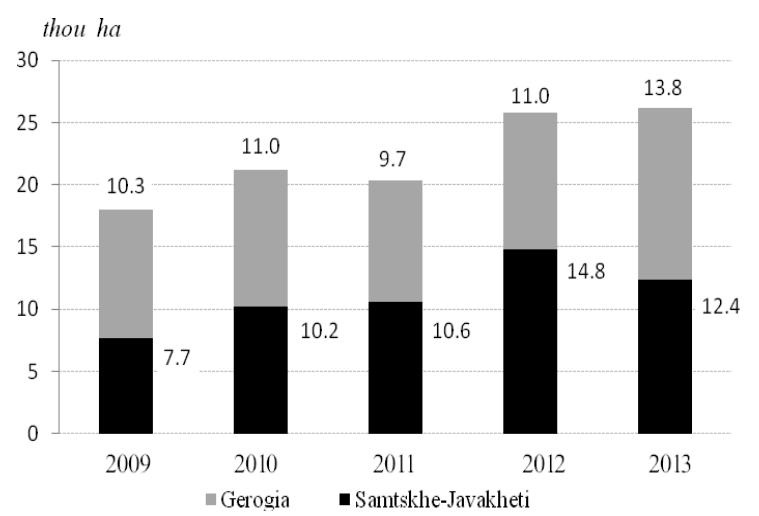

Figure 5. Area and Productivity of Potato in Georgian and Samtskhe-Javakheti, in 2011-2013.

According to 2014 year data, in Georgia, $36 \%$ of the total potato area is in Samtskhe-Javakheti (Fig. 5). It exceeds all regions with its average potato harvesting, however, in recent years (2009-2013) Its sharp reduction from 17.7 to $13.2 \mathrm{t} / \mathrm{ha}$ is obvious. At the same period in other regions (Adjara, Shida Kartli region), on the contrary, potato average productivity, a small, but the growth of tendencies have been revealed. Exactly, the reduction of potato productivity in Samtskhe-Javakheti, conditioned reduction of average index of Georgia[8].

Perennial crop has always been an important activity for the population of Samtskhe Javakheti. Especially - fruit-growing and viticulture. Although over the past decades a leading position has been taken by the fruit-growing. In region perennial plants are common only within the Akhaltsikhe basin.

Fruit production has decreased considerably over the years 2009-2011 (reduction was about 2.4\%). As compared to 2012, its share in 2013 has increased by almost $38 \%$ (5.1 to 8 at. Tones). This decrease mainly comes from seed fruit, especially apples (in 2013 is only 1/3 of 2009 year production) [9].

Thus, we face productivity reduction tendencies almost in all sections of agriculture in Samtskhe-Javakheti region. On this background, remaining the total number of production and progress in this direction can be achieved by increasing the area, by increasing agro-technical service level and by effective use of mineral fertilizers and chemicals. However, because of the lack of households and of a technical level, those activities will inevitably lead to the ecological condition deterioration, contamination of the obtained products.

Samtskhe-Javakheti region is one of the main Cattle breeding region in Georgia. Samtskhe-Javakheti has a significant share of the total cattle-breeding production (from the total number, approximately $8-17 \%$ comes for the region). Average yield of milk is about $15 \%$ higher than the national average . In the country, about $9-14 \%$ of the total livestock is concentrated in the region.

Till 1990s, in Samtskhe-Javakheti region was a quite high cattle live-stock, which existed on state farms and in the private ownership of rural communities. Currently cattle life-stock is pretty much reduced and they appear to be only in rural population's private ownership. This has reduced the pressure on pastures.

In recent years cattle life-stock growth tendency is noticed in municipalities of Ninotsminda, Akhaltsikhe and Adigeni. Especially sharp increase is in Ninotsminda District. Although life-stock is decreased in Borjomi municipality (by 500 of life-stock).

During the years 2000-2013 cattle increase and lamb life-stock decrease is observed. Cattle's life-stock was increased 1.5 times, while lamb's life-stock was decreased 1.5 times (Fig. 6).

In the region approximately $10 \%$ of the existing total Bee's family members, is concentrated in the country (Tab. 2). It's an interesting fact, that in 200-2013, there has been an increase in the total number of bee hives in Georgia. The same tendency is observed in Samtskhe-Javakheti. Although, the 
region lags behind the average pace of growth. In Georgia the number of bee hives was increased 4-times, while in Samtskhe-Javakheti it was increased 3times. Poultry and bee families are mainly concentrated in Akhalkalaki municipality [10].

Information about cattle breeds composition and knowledge among local farmers is scarce. Megrelian and local varieties is widely distributed. Artificial insemination is less developed and therefore breeding, basically, is out of control. This leads to the degeneration of the species and the negative impact on livestock productivity, health, and growth and development of organism resistance.

Table 2. Bee life-stock, 2000-1013.

\begin{tabular}{|c|c|c|c|c|c|c|c|c|c|c|c|c|c|c|}
\hline Region's Share \% & 8 & 8 & 8 & 9 & 8 & 8 & 11 & 10 & 8 & 10 & 11 & 12 & 9 & 8 \\
\hline Georgia & 547 & 568 & 611 & 629 & 689 & 720 & 697 & 711 & 690 & 602 & 597 & 577 & 688 & 796 \\
\hline Samtskhe-Javakheti & 115 & 87 & 94 & 97 & 89 & 88 & 90 & 73 & 62 & 87 & 75 & 72 & 81 & 78 \\
\hline Region's share & 21 & 15 & 15 & 15 & 13 & 12 & 13 & 10 & 9 & 5 & 13 & 13 & 8 & 10 \\
\hline
\end{tabular}

Cattles in winter are mostly fed with grass, combined food (silos is not used) Is rarely used, which is why there is a low productivity and weight loss of cattle.

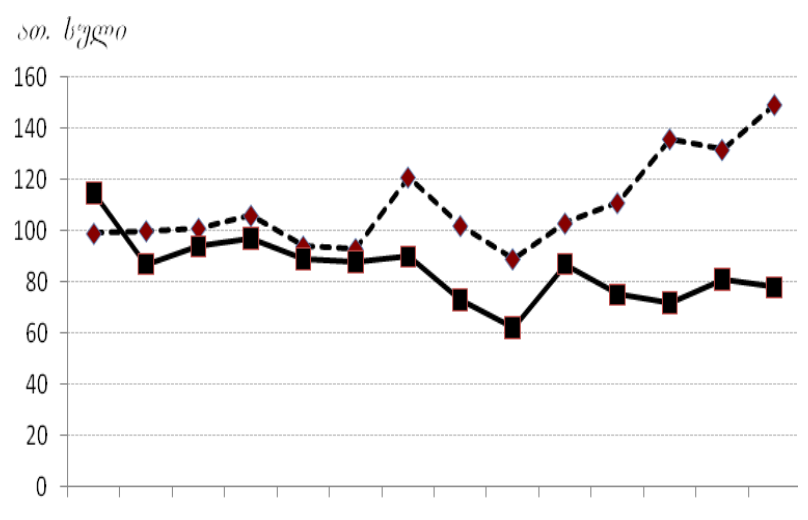

20002001200220032004200520062007200820092010201120122013

$$
-\infty-\text {-Cattle } \quad-\square \text { Sheet }
$$

Figure 6. Number of cattle and Sheet in Samtskhe-Javakheti, 2011-2013.

Pastures in the region, mainly are in common use, and they are characterized by a variety of problems (pasture degradation). Their productivity has been decreased significantly. However, even with a simple pasture rotation system's inculcation, it is possible to reduce soil erosion by $15 \%$ during the first year and an additional $5 \%$ each subsequent year (during5 years). Pasture rotation system implementation will increase productivity by more than $20 \%$, and which will reduce the quality of overgrazing. Veterinary services in the region often lack adequate levels - some communities do not have a veterinarian and the farmers are forced to apply for municipal centers or neighboring communities assistance. During the summer there are many diseases, such as "Turkish" and "anthrax" .

Part of the Samtskhe-Javakheti territory is a summer pasture and domestic animals migration from plain regions is frequent. Cattle driveways and summer camps are not in an appropriate condition, considering these various spreading diseases, it causes even bigger threat. In addition, the municipalities have an absence of modern laboratories that prevents animal diseases ascertaining in a timely manner.

\section{Conclusions}

Samtskhe-Javakheti agriculture special role is ensured by agricultural resources diversity and by the development of traditional sectors. In recent years, by the slight growth of agricultural culture areas average and total productivity reducing tendencies have been revealed.

In regions plant growing, potato is the first culture. In the country, Samtskhe-Javakheti holds more than third of occupied by culture area and an important share of production. in addition, comparing with other regions, in spite of the high average productivity, over the last years (2009-2013 years) its sharp downward tendencies are evident on the background of small growth of average productivity in other parts of Georgia that lead to average Georgia index reduction.

Livestock has historically been one of the most important branches of Samtskhe-Javakheti Agriculture. Compared to other regions of the country on the background of cattle high life-stock, after 1990s, the sharp decrease is observed. However, in recent years is a significant life-stock cattle growth tendency.

Because of the lack of industrial facilities, in this side, pollution caused by industrial wastes and emission, is relatively less. That's why ecological problems mainly occur because of excessive use of mineral fertilizers and chemicals, household waste utilization system disorder, a common infrastructure poor condition.

Due to research several problems have been revealed: related to "chemicalization" (excessive use of chemicals fertilizers, growth stimulants for plant protection, soil contamination with heavy metals), biological and Household waste (breeding farms waste, domestic waste), soil and water supply protection Household waste (breeding farms waste, domestic waste), soil and water supply protection (overgrazing, lack of windbreaks, soil erosion, irrigation systems malfunctions) and others. Those problems greatly hinders the development of agriculture and it occurs to be the greatest challenge for the region population, that is mostly employed in the agricultural sector.

Special importance was attached to research done on the basis of the different types of soil humus and nutrient stocks, soil structure, and its physical properties. Meadow alluvial, humus-carbonate, gray-brown soils and calcareous have been studied.

Ecological problems solution and agricultural production's sustainable development activation, which will ensure ecological condition improvement in agricultural sectors and getting rid of pollution of environment, providing the local population with healthy products. That will create a firm foundation for withdrawing the agricultural production import . 


\section{Acknowledgements}

The research was done on the basis of the project "Landscape-ecological evaluation of Samtskhe-Javakheti with GIS analysis for territorial planning" (\#AR/105/9-280/13), which is funded by Shota Rustaveli National Scientific Foundation. The authors thank the Fund who provided and greatly assisted the research.

\section{References}

[1] Didebulidze A. Agriculture development in Georgia. Tbilisi,1997. In Georgian.

[2] Neidze V. Geography of Georgia. II part. "Socio-economic geography". Tbilisi. 2003. In Georgian.

[3] Geography of Georgia. part II. Social-Economic Geography.
Academy of sciences of Georgia. Vakhushti Bagrationi institute of Geography. Tbilisi.2003. In Georgian.

[4] Geography of Georgia. part II. Historical-Geographical Regions. noun editor M. Alfenidze. Tbilisi, 2001. In Georgian.

[5] Lomsadze Sh. Samcxe-Javaxeti, Tbilisi, 1975. In Georgian

[6] Gogsadze G. Population Geography. Tbilisi, 2008. In Georgian.

[7] Jaoshvili V. "Agriculture of Georgia". Tbilisi, 1996. In Georgian.

[8] Samtskhe-Javakheti Development Strategy. Samtskhe-javakheti.gov.ge/.../pdf28-Javakheti. In Georgian.

[9] Samtskhe-Javakheti Regional Administration. Samtskhe-javakheti.gov.ge/main.php?lang=geo\&act=pages

[10] National Statistics Office of Georgia. www.geostat.ge. 